\title{
An NSGA-II Algorithm with Adaptive Local Search for a New Double-Row Model Solution to a Multi-Floor Hospital Facility Layout Problem
}

\author{
Jiazhen Huo, Jing Liu and Hong Gao *
}

Citation: Huo, J.; Liu, J.; Gao, H. An NSGA-II Algorithm with Adaptive Local Search for a New Double-Row Model Solution to a Multi-Floor Hospital Facility Layout Problem. Appl. Sci. 2021, 11, 1758. https:// doi.org/10.3390/app11041758

\section{Academic Editor:}

Alexandre Carvalho

Received: 31 January 2021

Accepted: 12 February 2021

Published: 16 February 2021

Publisher's Note: MDPI stays neutral with regard to jurisdictional claims in published maps and institutional affiliations.

Copyright: (c) 2021 by the authors. Licensee MDPI, Basel, Switzerland. This article is an open access article distributed under the terms and conditions of the Creative Commons Attribution (CC BY) license (https:// creativecommons.org/licenses/by/ $4.0 /)$.
Department of Management Science and Engineering, Tongji University, Shanghai 200092, China; huojiazhen@163.com (J.H.); 1832778@tongji.edu.cn (J.L.)

* Correspondence: gloriahgao@163.com

\begin{abstract}
A well-designed hospital facility layout planning process will enable improvements in operational efficiency, health outcomes, and patients' medical experience. Older hospital facility layouts are likely to be based only on their designer's experience, extant legal regulations, and other historical constraints. In this paper, we propose a solution to a multi-floor hospital facility layout problem in a hospital in Shanghai, China, based on a double-row model in which all departments are arranged into two rows on each floor. In this model, some fixed facilities are also taken into consideration. Two objectives, namely minimizing the total movement distance of patients and maximizing the total closeness rating score, are considered. An NSGA-II (nondominated sorting genetic algorithm II) algorithm with an adaptive local search operator has been developed to search for Pareto-optimal solutions. Experimental results show that our algorithm is able to solve model requirements successfully, the local search operator performs well, and the obtained results outperform the present layout in both the objectives.
\end{abstract}

Keywords: hospital facility layout problem (HFLP); multi-objective optimization; genetic algorithms; adaptive local search; Pareto-optimal solution

\section{Introduction}

With the enhanced demands of healthcare provision, many hospitals are facing intense pressure to improve efficiency and provide better medical services to more patients [1-4]. According to a report from the National Bureau of Statistics of China, the number of yearly visits to all kinds of healthcare institutions increased from 4.9 billion in 2007 to 8.3 billion in 2018. The growing demand for healthcare services leads to increased demand upon new hospital buildings as well as the renovation and re-purposing of existing ones [4]. Many hospitals are considering reconstructing their old buildings and facilities to optimize the patient treatment process by significantly rearranging hospital layouts. An unprecedented healthcare facility construction boom in the United States has shown the importance of creating optimal physical environments to achieve the best possible outcomes for patients, families, and staff [5]. Ulrich and Zhu [6] addressed the serious negative effects of suboptimal transport paths on patient outcomes and highlighted that it is necessary to improve the designs of hospitals in order to reduce patient transport distances and delays.

Solving the facility layout problem (FLP) involves finding the most efficient arrangement of elements on the factory floor subject to different constraints in order to meet one or more objectives $[7,8]$. An effective facility layout design can increase throughput, overall productivity, efficiency [9], and alleviates congestion [10]. The FLP has been studied for decades and applied to many diverse problems, such as printed circuit board design; the layout design of hospitals, schools, and airports; backboard wiring problems; typewriters; warehouses; and hydraulic turbine design [11]. One of the most important indicators of the efficiency of a layout in manufacturing industry is the material handling cost (MHC) [12], 
since $20-50 \%$ of the total operating costs of a manufacturing company and $15-70 \%$ of the total cost of manufacturing a product are attributed to MHC [13]. Thus, companies can improve productivity and reduce these costs by $10-30 \%$ if their facilities are arranged effectively [14]. Conversely, an ineffective layout may add as much as $36 \%$ to MHC [8]. Research indicates that more than $35 \%$ of system efficiency is likely to be lost due to incorrect layouts and location designs [15]. Hence, the issue of the FLP is one of the most important factors for resolution in the literature of production management and industrial engineering, attracting the attention of many researchers [16].

The term hospital facility layout problem (HFLP) refers to the application of facility layout theory and practice to a healthcare management context. From the perspective of management, the HFLP belongs to the strategic level of resource capacity planning and decision-making [17]. It aims to find the most efficient solutions to long-term efficiency and effectiveness decisions. The HFLP has a great impact on medical quality, job satisfaction for medical and other staff, and patient satisfaction [18-23]. However, in practice, hospital buildings are often planned by architects based on their general experience and whatever legal regulations are extant at the time of commissioning [24-28], thus, without specific healthcare considerations being taken into account, re-design will be unable to guarantee whether the layout is optimal and fit for purpose. Therefore, considering the HFLP is an essential practice and the problem should be modelled through mathematics and address relevant holistic, applied, and specific factors. In the HFLP, total movement distance (or cost, by assigning unit cost to movement) of patients is the indicator most often used for evaluating layout. Long movement distances between departments waste time, are resource-inefficient, and reduce patient satisfaction, especially for people who are seriously ill [4] adding unnecessary burden to medical and ancillary staff. Apart from total movement distance, which is used to measure the logistics efficiency, a closeness rating chart is often used in assessing the HFLP to measure non-logistical factors such as safety, cleanness, noise, and so forth $[25,28]$.

In this paper, we propose a novel multi-objective double-row model for the multi-floor HFLP of a working hospital in Shanghai, China. In this model, both logistical factors (movement distance and path) and non-logistical factors (closeness rating) are taken into account. Additionally, some fixed facilities, the locations and dimensions of which are unchangeable according to the hospital's requirements, are considered. Because the model is a nondeterministic polynomial problem, a novel heuristic has been designed to search for Pareto-optimal solutions. Data from the hospital is used for computational experiments to test the model and the algorithm we present.

In conclusion, the main contributions of this paper are as follows:

1. The paper presents a novel multi-objective double-row model suitable for a multifloor HFLP which minimizes the movement distance of patients and maximizes the closeness relationships between departments by considering the patient's medical experience and the relationship between various departments of the hospital. Obtained results outperform actual layout in both of the objectives.

2. An NSGA-II (nondominated sorting genetic algorithm II) algorithm with improved local search ability has been developed to solve the multi-objective model, the effectiveness of which is positively evaluated.

The remaining part of the paper is organized as follows. In Section 2, we present a detailed review of previous research on HFLPs. In Section 3, the problem under investigation is described in detail. In Section 4, the multi-objective double-row model is presented. The detail of our proposed algorithm is illustrated in Section 5. In Section 6, real data from the hospital is used to examine the effectiveness of the model and the performance of the algorithm that we propose, and the paper is finalized with conclusions and discussions in Section 7. 


\section{Literature Review}

The existing research on the HFLP is mainly based on QAP (quadratic assignment problem) models and MIP (mixed integer problem) models. One of the earlier researches on the HFLP was proposed by Elshafei [29] as a QAP model. Feng and Su [30] proposed a QAP model to solve the problem of different department sizes. Helber et al. [31] presented a QAP model that can be used for the overall facility layout of a large general hospital. Rismanchian and Lee [4] applied process-mining technology to analyze the pathway of patients and discover the patient flows between departments. They developed a multi-objective model which took distance, design preference, and relocation cost into consideration to improve the efficiency of an emergency department. Arnolds and Gartner [32] also applied a process-mining method and built a QAP model to find the optimal layout.

QAP models are NP-hard and it is difficult to obtain optimal solutions by exact procedure when the problem scale is large. Therefore, some papers have developed different meta heuristics to solve large-scale QAP models. Liang and Chao [33] proposed a tabu search algorithm to solve the QAP model. Mohamed et al. [34] integrated the whale algorithm with tabu search to solve the QAP model and determine the location of each department of a hospital. Tayal and Singh [35] applied big data analysis to find out factors that have the greatest impact on the layout design. Then they used a hybrid firefly simulated annealing algorithm to solve the QAP model. Tongur et al. [36] used three different algorithms, namely migrating bird optimization, simulated annealing, and tabu search, to solve a large-scale hospital layout problem. Because of the discreteness of the solutions, QAP models can only be used for problems where all the potential locations are determined prior to the calculation.

MIP models are used in a continuous layout representation that is an extension of the discrete QAP model [11]. However, research in this field is not abundant. In MIP models, departments can be located anywhere as long as all identified constraints are satisfied. In practice, many hospitals arrange their departments into rows $[1,2,24,26,27,37-39]$. Therefore, the most relative research in this area considers how to arrange departments into several rows more reasonably, so as to improve the efficiency of the hospital. Arnolds and Nickel [24] addressed a multi-period layout planning problem of hospital wards, which aims at minimizing either the number of demand violations or costs for installing fixed patient rooms. In their model, the wards are arranged in two rows in each period. A series of layout problems of operating theaters was discussed by Chraibi et al. [1,2,26,27,38]. In these researches, all considered departments were arranged into either two rows $[1,2,26,27]$ on one floor or three rows on several floors [38]. Among the above researches, no fixed facility is considered, and all floor spaces are available for planning layout. The models of MA et al. [37] and Zuo et al. [39] both considered the layout problem of emergency departments similar to ours, as they also arrange departments into rows while considering some fixed facilities. MOEA/D (multi-objective evolutionary algorithm based on decomposition) [37] and tabu search [39] are used to search for optimal solutions. However, their models and algorithms are based on a single-floor problem. Additionally, even in researches where some facilities are fixed they have little influence on the layout planning process. In this paper, fixed facilities play an important role and can be regarded as obstacles that limit the potential locations of the departments.

There are previous studies regarding general double-row models, however, this paper is also different from them. The double-row (or multi-row) model considers a special kind of FLP which involves arranging a number of rectangular facilities of varying widths on both sides of a straight-line corridor (or corridors in multi-row models) to minimize the total cost of material handling between facilities [16]. One of the pioneer researches on this model is proposed by Chung and Tanchoco [40]. Five heuristics were developed to generate good initial solutions, and they solved the model by CPLEX (IBM, Armonk, New York, USA). Since then, some studies have extended this model and developed more efficient methods to solve the model. An efficient local search heuristic was proposed by Murray et al. [41] for the double-row model. A multi-objective tabu search algorithm 
combined with linear programming was proposed by Zuo et al. [42] to solve the doublerow model. The objective is to determine the exact locations of the machines in both rows by minimizing material handling cost and layout area. Wang et al. [43] considered the application of the double-row model in dynamic environments where material flows change over time in different processing periods and developed an improved simulated annealing (ISA) to solve the problem. Amaral and André [44] improved the formulation of the double-row model. The new model has the advantage of being more intuitive for handling qualitative inputs that may be required in a layout refinement phase. Compared with the above researches, this paper considers two special requirements of hospital, namely closeness rating and fixed facilities, thus, our model is a new application and improvement of the general double-row model for solving the HFLP.

\section{Problem Statement}

In this paper, let $N$ be the number of rectangle departments to be placed, without any overlap, on $F$ floor space. Each department $i$ is defined by its dimensions $\left(w_{i}, l_{i}\right)$ with area requirements $a_{i}=w_{i} * l_{i}, i=1, \ldots, N$. Besides the departments to be arranged, there are also a series of fixed facilities, the positions and dimensions of which are unchangeable due to the requirements of the hospital. No department can overlap any fixed facility. All the departments are arranged into two rows on each floor. Different from the general doublerow model, the width and length of the two rows are not the same. The dimensions of the two rows, the lower row and the upper row, are $\left(l r_{1}, w r_{1}\right)$ and $\left(l r_{2}, w r_{2}\right)$, respectively. Note that the centers of the two rows are aligned vertically. A corridor, with the dimensions $\left(l r_{1}\right.$, $\left.w_{c}\right)$, is horizontally lined between the two rows. Halls with dimensions $\left(l_{h}, w r_{1}+w_{c}\right)$ are located in the middle of each floor, overlapping the lower row and the corridor. Elevators are located inside the hall and are assumed to be a series of points, without area requirement, on coordinates $\left(x e_{i}, y e_{i}\right)(i=1, \ldots, e)$, respectively. An example of empty floor space is depicted in Figure 1, where the green areas are available space where departments can be placed; the elevators are represented by two red points. A layout is defined by the $\mathrm{x}$-coordinates $x_{i}$ of the centroid, the horizontal $w_{i}$ and vertical $l_{i}$ dimensions, the located row $y_{i r}$, and the located floor $l f_{i}$ of department $i$. We use the total movement distance of patients as the first objective, based on quantitative factors, and the closeness rating score of departments based on qualitative factors as the second objective. The notations used in the formulation are presented in Table 1.

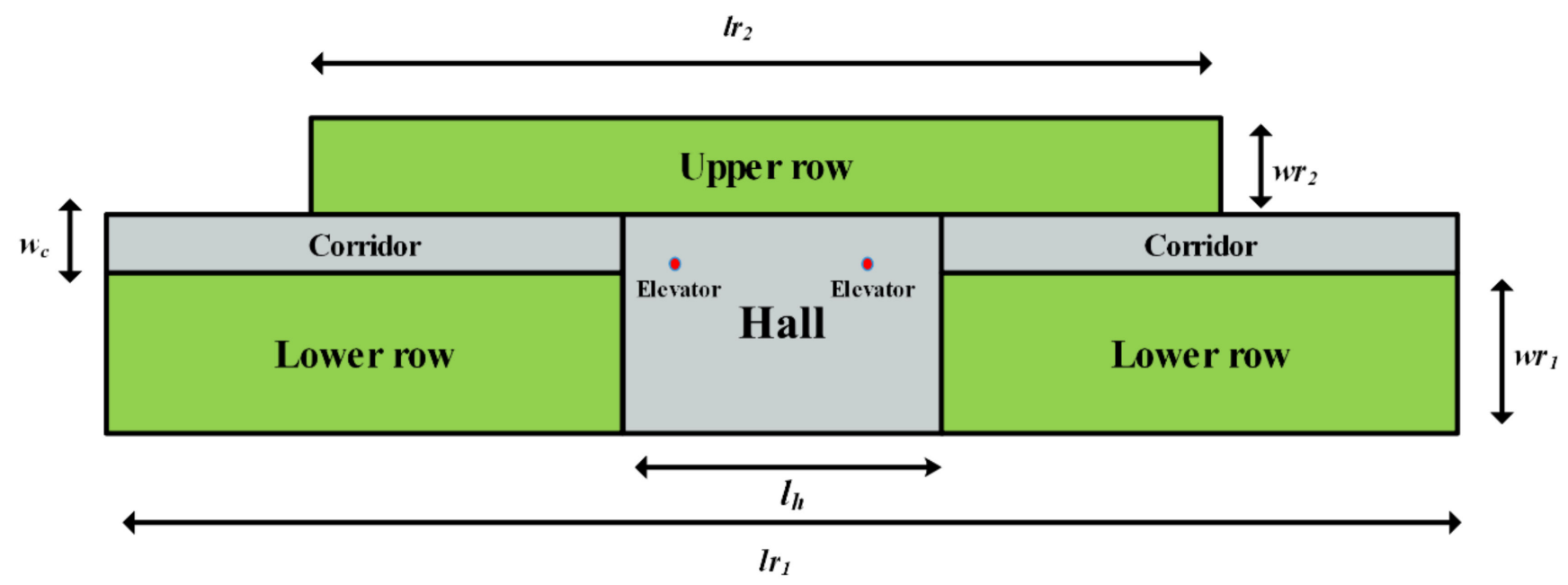

Figure 1. An empty floor space. 
Table 1. Notations used in the formulation.

\begin{tabular}{|c|c|}
\hline Indices & \\
\hline \multicolumn{2}{|l|}{ Sets } \\
\hline$N=\{1,2, \ldots, n\}$ & Set of departments to be located \\
\hline$M=\{1,2, \ldots, m\}$ & Set of fixed facilities \\
\hline$E=\{1,2, \ldots, e\}$ & Set of elevators \\
\hline$F=\{1,2, \ldots, f\}$ & Set of floors \\
\hline$R=\{1,2\}$ & Set of rows, 1 for the lower row and 2 for the upper row \\
\hline \multicolumn{2}{|l|}{ Input variables: } \\
\hline$l r_{1}, w r_{1}$ & The width and length of the lower row \\
\hline$l r_{2}, w r_{2}$ & The width and length of the upper row \\
\hline $\mathrm{H}$ & The height of each floor \\
\hline$c_{i j}$ & The patient flow between department $i$ and $j$ \\
\hline$r_{i j}$ & The closeness rating between department $i$ and $j$ \\
\hline$a_{i}$ & The area requirement of department $i$ \\
\hline$l_{h}$ & The length of the hall \\
\hline$w_{c}$ & The width of the corridor \\
\hline$x e_{i}, y e_{i}$ & The $\mathrm{x}$ - and $\mathrm{y}$ - coordinates of elevator $i$ \\
\hline l_fixed & The length of the fixed facility $i$ \\
\hline floor_fixed $_{i}$ & The located floor of the fixed facility $i$ \\
\hline row_fixed & The located row of the fixed facility $i$ \\
\hline$x_{-}$fixed $_{i}$ & The $x$ - coordinate of the central point of the fixed facility $i$ \\
\hline$n$ & The total number of departments \\
\hline$m$ & The total number of fixed facilities \\
\hline$e$ & The total number of elevators \\
\hline$f$ & The total number of floors \\
\hline$P$ & Penalty factor \\
\hline$M$ & A very large value \\
\hline \multicolumn{2}{|l|}{ Decision variables: } \\
\hline$x_{i}$ & The $\mathrm{x}$ - coordinate of the central point of department $i$ \\
\hline$l_{i}$ & The length of department $i$ \\
\hline$w_{i}$ & The width of department $i$ \\
\hline$d_{i j}$ & The total movement distance between department $i$ and $j$ \\
\hline$d_{i j}^{c}$ & The rectilinear distance between department $i$ and $j$ \\
\hline$b_{i j}$ & The adjacency factor between department $i$ and $j$ \\
\hline$d e_{i}$ & The distance between department $i$ and the nearest elevator \\
\hline & A binary variable which is equal to one if department $i$ is \\
\hline$y_{\text {ir }}$ & located in row $r$ or is zero otherwise \\
\hline$l f_{i}$ & The floor in which department $i$ is located \\
\hline$A_{i k}$ & $\begin{array}{c}\text { A binary variable which is equal to one if department } i \text { is } \\
\text { located in floor } k \text { or is zero otherwise }\end{array}$ \\
\hline$B_{i j}$ & $\begin{array}{c}\text { A binary variable which is equal to one if department } i \text { and } j \\
\text { are located on the same floor or is zero otherwise }\end{array}$ \\
\hline$F_{i j}$ & $\begin{array}{l}\text { A binary variable which is equal to one if department } i \text { and } j \\
\text { are located in the same row of same floor or is zero otherwise }\end{array}$ \\
\hline
\end{tabular}

The assumptions in this paper are described as follows:

1. Patients move between two departments which are not on the same floor by elevators located inside the hall. The elevators are regarded as a series of points that do not occupy any actual floor space.

2. The vertical distance between two adjacent floors is equal to a fixed floor height.

3. The doors of departments are located in the midpoint of each department's edge that is adjacent to the corridor. Patients move between doors when they want to move to another department.

4. Patients always follow the shortest path when moving between two departments. Patients cannot pass through any departments and can only move along the $\mathrm{X}$ or $\mathrm{Y}$ axes. That is to say, all patients' movements are along corridors.

5. No department can be located in the hall or overlap the hall 


\section{Model Formulation}

Our new double-row model can be formulated as follows:

Objective functions:

$$
\begin{aligned}
\min F_{1} & =\sum_{i=1}^{N-1} \sum_{j=i+1}^{N} c_{i j} \cdot d_{i j} \\
\max F_{2} & =\sum_{i=1}^{N-1} \sum_{j=i+1}^{N} r_{i j} \cdot b_{i j}
\end{aligned}
$$

Subject to:

$$
\begin{aligned}
& d e_{i}=\min _{e}\left\{\left|x_{i}-x_{t}\right|+\left|y_{i 1} w r_{1}+y_{i 2}\left(w r_{1}+w c\right)-y_{t}\right|\right\} \forall i \in N, \forall t \in E \\
& d_{i j}=B_{i j}\left[F_{i j}\left|x_{i}-x_{j}\right|+\left(1-F_{i j}\right)\left(\left|x_{i}-x_{j}\right|+w c\right)\right]+\left(1-B_{i j}\right)\left(d e_{i}+d e_{j}\right)+H\left|f_{i}-f_{j}\right| \forall i, j \in N \\
& \sum_{k=1}^{f} A_{i k}=1 \forall i \in N \\
& \sum_{k=1}^{f} k A_{i k}=l f_{i} \forall i \in N \\
& \sum_{k=1}^{f} A_{i k} A_{j k}=B_{i j} \forall i, j \in N \\
& \sum_{r=1}^{2} y_{i r}=1 \forall i \in N \\
& B_{i j} \sum_{r=1}^{2} y_{i r} y_{j r}=F_{i j} \forall i, j \in N \\
& l_{i}=y_{i 1} \frac{a_{i}}{w r_{1}}+y_{i 2} \frac{a_{i}}{w r_{2}} \forall i \in N \\
& \left|x_{i}-x_{j}\right| \geq \frac{1}{2}\left(l_{i}+l_{j}\right)+M\left(F_{i j}-1\right) \forall i, j \in N \\
& \mathrm{x}_{i} \geq \frac{1}{2} y_{i 1} l_{i}+\frac{1}{2} y_{i 2}\left[\left(l r_{1}-l r_{2}\right)+l_{i}\right] \forall i \in N \\
& \mathrm{x}_{i}+\frac{1}{2} l_{i} \leq y_{i 1} l r_{1}+\frac{1}{2} y_{i 2}\left(l r_{1}+l r_{2}\right) \forall i \in N \\
& y_{i 1}\left|x_{i}-\frac{1}{2} l f_{1}\right|+M\left(1-y_{i 1}\right) \geq \frac{1}{2}\left(l_{i}+l h\right) \forall i \in N \\
& M\left(y_{i, \text { row_f }_{-} \text {ixed }_{p}} A_{i_{\text {floor_fixed }}}-1\right)+\frac{1}{2}\left(l_{i}+l_{\text {fixed }}\right) \leq\left|x_{i}-x_{\text {fixed } p}\right| \forall i \in N, \forall p \in M \\
& w_{i}=\frac{a_{i}}{l_{i}} \forall i \in N \\
& w_{k}^{a v g}=\frac{\sum_{i=1}^{N} A_{i k} \cdot w_{i}}{\sum_{i=1}^{N} A_{i k}} \forall k \\
& l_{k}^{a v g}=\frac{\sum_{i=1}^{N} A_{i k} \cdot l_{i}}{\sum_{i=1}^{N} A_{i k}} \forall k \\
& d_{i j}^{c}=B_{i j} \cdot\left(\left|x_{i}-x_{j}\right|+\left|\left(\frac{1}{2} y_{i 1} w r_{1}+\left(1-y_{i 1}\right)\left(w r_{1}+w_{c}+\frac{1}{2} w r_{2}\right)\right)-\left(\frac{1}{2} y_{j 1} w r_{1}+\left(1-y_{j 1}\right)\left(w r_{1}+w_{c}+\frac{1}{2} w r_{2}\right)\right)\right|\right)+ \\
& M\left(1-B_{i j}\right) \quad \forall i, j
\end{aligned}
$$




$$
b_{i j}=\left\{\begin{array}{ll}
0 & \frac{d_{i j}^{c}}{w_{k}^{a v 0}+l_{k}^{a v g}} \geq 5 \\
0.2 & 5>\frac{d_{i j}^{c}}{w w_{k}^{a v g}+l_{k}^{a v g}} \geq 4 \\
0.4 & 4>\frac{d_{i j}^{c}}{w_{k}^{a v g}+l_{k}^{a v g}} \geq 3 \\
0.6 & 3>\frac{d_{i j}^{c}}{w_{k}^{a v g}+l_{k}^{a v g}} \geq 2 \\
0.8 & 2>\frac{d_{i j}^{c}}{w_{k}^{a v g}+l_{k}^{a v g}} \geq 1 \\
1 & 1>\frac{d_{i j}^{c}}{w_{k}^{a v g}+l_{k}^{a v g}}>0
\end{array} \quad \forall i, j, k ; B_{i j}=1, A_{i k}=1, A_{j k}=1\right.
$$

In the above formulations, the two objective functions, Equations (1) and (2), are used to minimize the movement distance of patients and maximize the closeness rating score weighted by adjacency factor, respectively. The minimum distance between department $i$ and all elevators is calculated by Equation (3). From Equation (4), the distance between two departments is determined by three factors: their coordinates, located floors, and located rows. When two departments are located on different floors, the distance between them is calculated by adding together three components: the minimum distance between department $i$ and elevators, the minimum distance between department $j$ and elevators, and the vertical distance which is calculated according to the height of each floor and the number of floors between departments. Equation (5) ensures each department can only be assigned to one floor using binary variable $A_{i k}$. From Equation (6), the located floor of department $i$ is determined. Equation (7) ensures $B_{i j}$ is equal to 1 only if departments $i$ and $j$ are on the same floor. Equation (8) ensures each department is located either in the lower row $(r=1)$ or the upper row $(r=2)$. By Equation (9), only if departments $i$ and $j$ are located in the same row of one floor will $F_{i j}$ be 1 . The length of department $i$ varies with the located row by Equations (10) and (11) is used to avoid any overlap between departments. Equations (12) and (13) ensure that all departments are located within the floor space. Equations (14) and (15) ensure no overlap between departments and the hall or the fixed facilities. The width of department $i$ is calculated by Equation (16). In order to calculate the closeness rating score, the average width and length of departments in each floor are firstly calculated by Equations (17) and (18), and the rectilinear distance between departments $i$ and $j$ is determined by Equation (19) only if the two departments are on the same floor, otherwise the rectilinear distance is set to a very large value $M$ which means the adjacency factor of the two department is zero in Equation (20). Then in Equation (20), the adjacency factor of each two departments is calculated based on the rectilinear distance between them and the average width/length of the departments on the floor.

\section{Proposed NSGA-II Algorithm with Adaptive Local Search}

The multi-objective model proposed in Section 4 is difficult to solve by exact procedure (e.g., CPLEX or Gurobi), due to its nonlinearity, binary variables, and multi-objective nature. In this paper, an NSGA-II algorithm with adaptive local search is proposed to search for Pareto-optimal solutions. NSGA-II is a kind of multi-objective genetic algorithm which was first proposed by Deb et al. [45] and has been widely used to search for Pareto-optimal solutions. NSGA-II has some advantages, such as fast nondomination sorting, the ability to maintain a good spread of solutions, and better convergence to the true Pareto front.

In general, genetic algorithm can perform a global search in the entire search space, but it is poor at exploring the search space within the convergence area generated by the genetic algorithm loop [8]. In practice, additional local search operators are commonly used to improve algorithm performance. In this paper, an NSGA-II algorithm with an adaptive local search scheme is proposed to solve the hospital facility layout problem. Unlike Ripon et al. [8], the design of our local search scheme is based on a simulated annealing algorithm. In the rest of this section, the main components of the algorithm, including 
coding solutions and constructing layouts, constraints handling, genetic operators, and the local search scheme are presented in detail. The complete algorithm procedure is summarized in Section 5.8.

\subsection{Chromosome Representation and Layout Construction}

In this paper, individuals are coded by integer sequences which represent the order in which departments are placed using the layout construction method described below. Each individual consists of $n$ genes, the same as the number of departments. For example, if there are three departments to be placed, an individual [1-3] that represents department 2 is placed first, then department 3 and department 1 are placed in order.

The layout construction process is similar to packing a series of items into boxes, in which departments can be regarded as "items" and floors can be regarded as "boxes". Before placing departments, the fixed facilities are identified, placed in given positions on floor spaces, and exist as obstacles in the later steps. Similarly, the halls are also regarded as fixed facilities which are located in the center of the lower row. The layout construction procedure begins by placing departments in the lower row of the first floor. The departments are placed according to the order represented by each individual. Fixed facilities located in each floor divide the available floor space into several smaller available spaces. We define a set $G$ which contains all the available spaces. When placing a department, the space which can accommodate the department and with the lowest located floor is preferred. For spaces on the same floor, the one in the lower row is preferred; also, the one with a smaller $\mathrm{x}$-coordinate of the left side is preferred compared to other spaces in the same row. Then the department is placed closely to the left side of the selected space and $G$ is updated by removing the selected space and adding the new space generated from this placement. Repeat the above steps until all departments are placed, then the total movement distance of patients and the total closeness rating score can be calculated. In order to place all departments, the length of the upper row of the last floor will be set to a large number which can accommodate all departments when constructing layout (the actual floor space will not be changed). This may cause some departments to be located outside the floor space, which is not reasonable and will be penalized by the penalty term in the Section 5.2.

A simple example of the layout construction process is depicted in Figure 2. Assume that there are three departments to be placed at one floor and the order of considered individuals is departments 2,3, then 1 . Additionally, two fixed facilities are located in the two rows, respectively. At first, there are three available spaces, G1, G2, and G3, in set G. The leftmost space in the lower row, G1, is selected and department 2 is located inside it. Then $G 1$ is removed from $G$ and a new space, $G 4$, is generated. $G 4$ cannot accommodate department 3, thus department 3 is placed at G2. Similar for department 1, it is then placed at G3. So far, the layout construction process of individual departments 2, 3, and 1 is finished. 

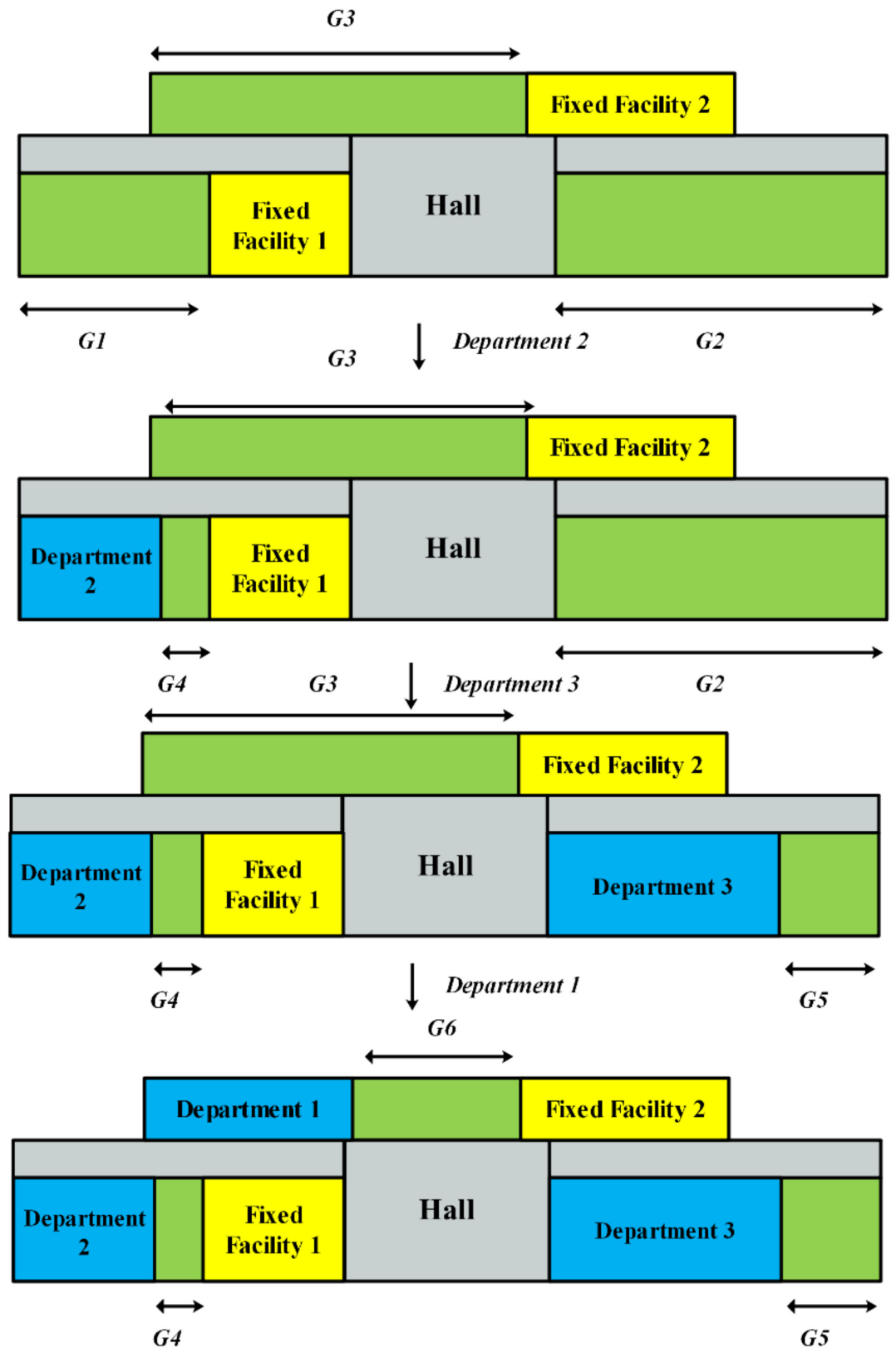

Figure 2. An example of a construction layout.

\subsection{Constraints Handling}

Using the layout construction method mentioned in Section 5.1, the obtained layouts can satisfy all the constraints in Section 4, except for Equation (13) which ensures all departments are placed inside the floor space. To ensure the departments are arranged in the available region of each floor, we introduce a penalty term. When any department is not fully located in the floor area (the right edge of the department is beyond the right edge of the floor space), a penalty term will be added to the two objective functions. For each department, the penalty term is calculated by using the following Equation (21)

$$
\text { penalty_ } x_{i}=\max \left\{0, x_{i}+0.5 l_{i}-w r_{2}\right\}
$$


Equation (21) is used to ensure that all departments are located in the floor area. Therefore, the above two objective functions in Section 4 should also be modified accordingly by adding the penalty term as follows:

$$
\begin{aligned}
\min F_{1} & =\sum_{i=1}^{n-1} \sum_{j=i+1}^{n} c_{i j} \cdot d_{i j}+P \sum_{i=1}^{n} \text { penalty_ } x_{i} \\
\max F_{2} & =\sum_{i=1}^{n-1} \sum_{j=i+1}^{n} r_{i j} \cdot b_{i j}-P \sum_{i=1}^{n} \text { penalty_ } x_{i}
\end{aligned}
$$

We calculate the nondomination rank and crowding-distance of each solution based on the objective values calculated by Equations (22) and (23) which are used in NSGA-II as selection and replacement operators.

\subsection{Selection Operator}

In this paper, a tournament selection strategy is implemented. The first two individuals are randomly selected from the current population. Then the one with the better nondomination rank wins the tournament and is copied to the next generation. If the two individuals belong to the same nondomination rank, the one with higher crowdingdistance is preferred. The individuals who win the tournament (the same as the population size $P s$ ) form the new population.

\subsection{Cross-Over Operator}

A single point cross-over strategy is adopted for the cross-over operator. Two parent individuals are randomly selected from the current population, then a cross-over point is randomly selected from the chromosomes, and the two parent individuals exchange their genes in front of the cross-over point to generate two new child individuals with a probability $p c$, where $p c$ is known as the cross-over probability. Otherwise, the two child individuals remain the same as the two parent individuals. After cross-over, a repair procedure is performed on the two child individuals. Genes behind the cross-over point will be replaced by the missing genes and remain in the same order as in the corresponding parent individual. Figure 3 shows an example of a cross-over operator.

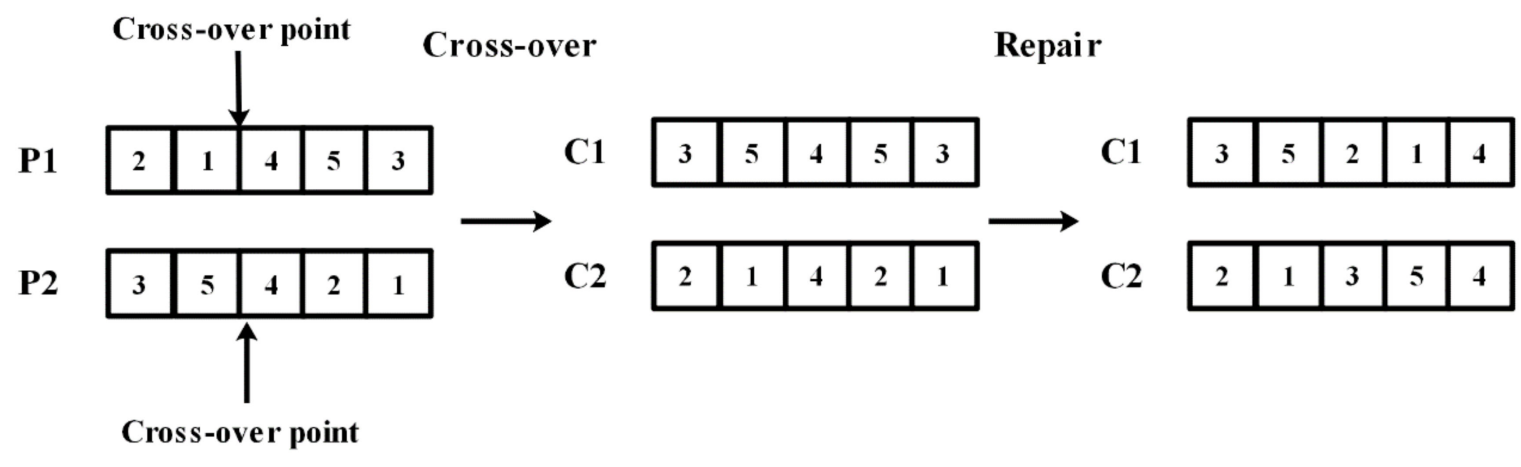

Figure 3. Schematic of a cross-over.

\subsection{Mutation Operator}

After cross-over, the mutation operator is implemented on the population to prevent premature convergence and to ensure the diversity of the population. In this process, each individual will be chosen to perform this procedure with an equal probability $\mathrm{pm}$, where $p m$ is known as the mutation probability. Three different mutation methods are designed and one of them will be chosen with the probability given as $p 1, p 2$, and $p 3$, respectively. Table 2 shows the three mutation methods in detail. Method 1 exchanges two genes of an individual and generates a new individual. Several consecutive genes are 
moved to a different position by using Method 2. Method 3 inverts the chromosome of the selected individual.

Table 2. Comparison of the three mutation methods.

\begin{tabular}{|c|c|c|c|c|c|c|c|}
\hline Method & & & & & \multicolumn{3}{|c|}{ Example } \\
\hline \multirow[b]{2}{*}{ Method 1: exchange } & \multicolumn{4}{|c|}{$\leftarrow$} & \multicolumn{3}{|c|}{$x$} \\
\hline & 2 & 1 & 3 & 5 & 4 & 7 & 6 \\
\hline \multirow[t]{2}{*}{ Method 2: insert } & 2 & 1 & 3 & 5 & 4 & 7 & 6 \\
\hline & 2 & 1 & 3 & 5 & 4 & 7 & 6 \\
\hline \multicolumn{8}{|l|}{ Method 3: invert } \\
\hline & 6 & 7 & 4 & 5 & 3 & 1 & 2 \\
\hline
\end{tabular}

\subsection{Replacement Operator}

After cross-over and mutation, there are $P s$ parent individuals and $P$ s offspring individuals in the current population, now referred to as the intermediate population. Next, the replacement operator is implemented to select the best $P_{s}$ individuals from the intermediate population for the next generation. Similar to the selection operator, whether an individual can be selected for the next generation is determined by its nondomination rank and crowding distance in the replacement operator. We select individuals with the best nondomination rank first. In other words, individuals ranked 1 are selected for the next generation first, then individuals ranked 2 and individuals ranked 3 , and so on sequentially. This procedure is continued until no more individuals can be accommodated. Assume that the individual ranked $l$ is the last nondominated individual set, beyond which no other set can be accommodated. Individuals with the largest crowding distance are selected to fill all population slots.

\subsection{Adaptive Local Search Operator}

To improve the performance of our algorithm we used an adaptive local search method based on a simulated annealing algorithm. Similar to Ripon et al. [8], the method is also based on the concept of similarity. When the genetic algorithm is continuously converging, the similarity among the individuals of a genetic algorithm population increases. Therefore, the fitness values of the individuals are similar to each other to a significant extent and the heterogeneity of the population is reduced [8]. The local search procedure will be invoked in a genetic algorithm loop when the similarity of the population exceeds a pre-defined threshold value $(\beta)$, otherwise only genetic algorithm is applied.

Compared with applying a local search in every iteration, the adaptive local search method takes much less time and produces high quality results. The similarity coefficient $S C_{p q}$ in our paper is calculated as follows:

$$
S C_{p q}=\frac{\sum_{k=1}^{n} \varphi\left(f_{p k}, f_{q k}\right)}{n}
$$

where $f_{p k}$ and $f_{q k}$ are the facilities at location $k$ in chromosomes $p$ and $q, k$ is the index of location in the layout, and $n$ is the number of facilities. The calculation of $\varphi\left(f_{p k}, f_{q k}\right)$ is as follows:

$$
\varphi\left(f_{p k}, f_{q k}\right)=\left\{\begin{array}{cc}
1 & \text { if } \\
0 & \left(f_{p k}=f_{q k}\right) \\
\text { otherwise }
\end{array}\right.
$$


The average similarity coefficient $\overline{S C}$ of the current population can be obtained by Equation (26) as follows:

$$
\overline{S C}=\frac{2 \sum_{p=1}^{P s-1} \sum_{q=p+1}^{P s} S C_{p q}}{P s *(P s-1)}
$$

where $P$ s refers to the size of population. When $\overline{S C}$ exceeds the threshold $\beta$, the local search procedure is applied to some individuals which are randomly selected from the population.

The process of the local search is described as follows. At first, all the relevant parameters are initialized. A new individual will be generated by the mutation methods in Section 5.5 and compared to the current individual. If the new individual dominates the current solution, the current individual will be replaced by the new individual. Otherwise, the current individual will be replaced by an acceptance probability calculated as Equation (27):

$$
P_{\text {accteptance }}=\prod_{i=1}^{2} \exp \left(-\frac{\left|f_{i}\left(X_{2}\right)-f_{i}\left(X_{1}\right)\right|}{T}\right)
$$

where the $T$ is the current temperature and $f_{i}\left(X_{2}\right)$ and $f_{i}\left(X_{1}\right)$ are the two objective function values of the new individual and the current individual, respectively. This process is repeated for loop_inner iterations, then the temperature is lowered by multiplying the cooling rate $\alpha$. The above process will be repeats until the temperature is lower than the final temperature $T \_$final.

\subsection{Summary of the Proposed Algorithm}

This NSGA-II algorithm with local search based on Pareto-optimization is our proposal for solving the new double-row model of a multi-floor HFLP with two objectives. The flowchart for the entire process is shown in Figure 4. First, after initializing all relevant parameters, $P_{S}$ initial individuals are created randomly. Those individuals form the initial population. For all individuals, the layouts can be obtained by using the construction procedure in Section 5.1 from which the objective function values are calculated. After that, the population is sorted based on nondomination rank, and each solution is assigned a rank equal to its nondomination rank and its crowding distance. The tournament selection operator, cross-over operator, and mutation operator are used successively to create $P s$ new offspring individuals. The best $P s$ individuals are selected from the intermediate population which is composed of the Ps parent individuals and the Ps new offspring individuals. If the average similarity coefficient $\overline{S C}$ of the current population exceeds a pre-defined threshold $\beta$, the adaptive local search procedure is applied to some individuals which are randomly selected from the current population. To this point, one iteration of the algorithm is completed. We repeat the above steps until the stopping condition is satisfied. The final product is a set of Pareto-optimal solutions. 


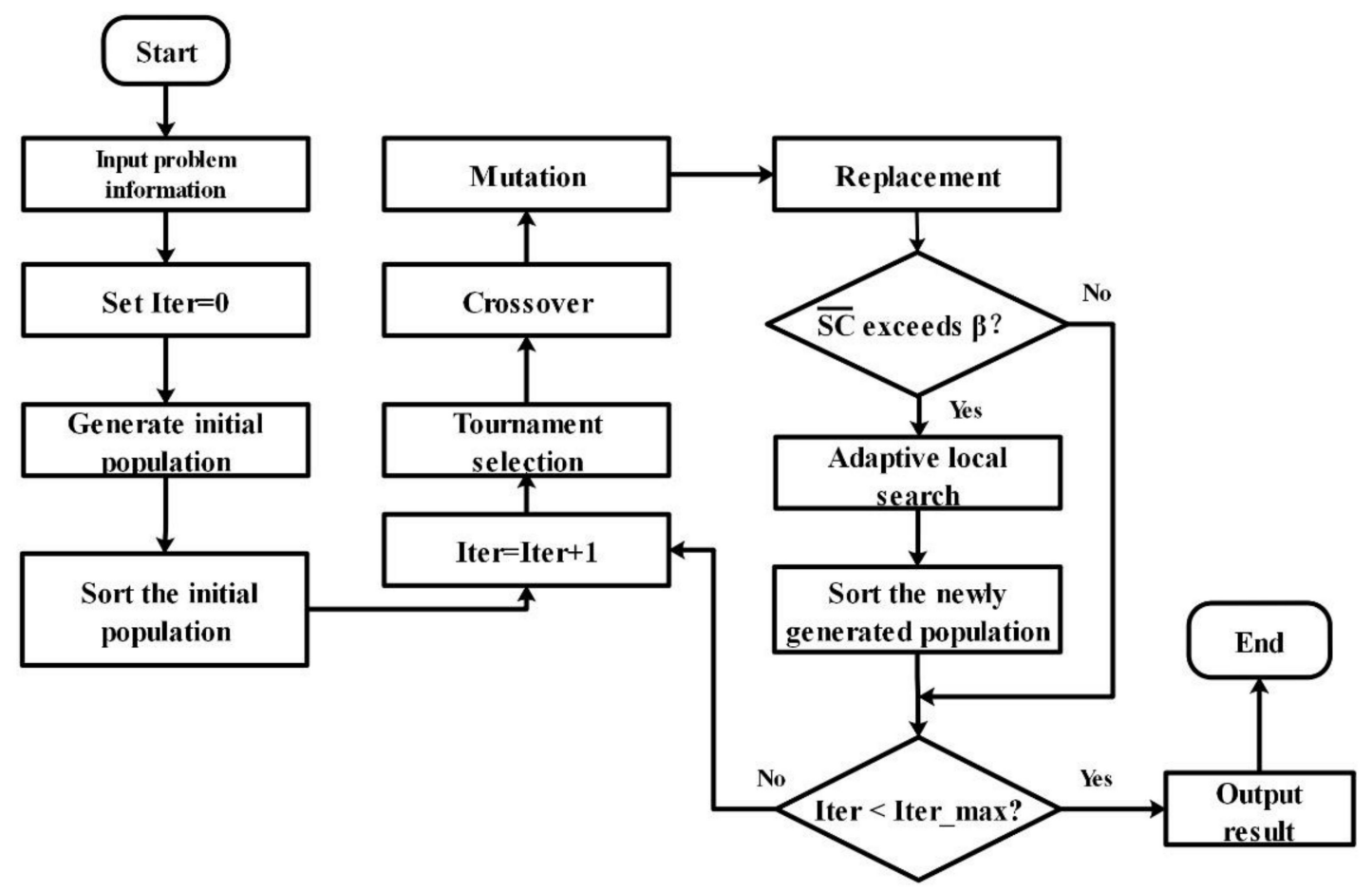

Figure 4. Flowchart of our algorithm.

\section{Computational Experiments}

\subsection{Experiment Setup}

In order to verify the validity of our model and evaluate the performance of the proposed algorithm, we performed a series of computational experiments using data from a working hospital. The proposed algorithm was coded in MATLAB 2019b and the data runs were conducted on a Windows 10 OS workstation using an Intel Xeon Gold 6142 CPU running at $2.60 \mathrm{GHz}$, with $256 \mathrm{~GB}$ of physical memory.

\subsection{Department Information and Patient Flow}

Table 3 records all the building-related parameters of the outpatient building of the hospital. There are 14 outpatient departments to be considered and their area requirements are listed in Table 4. The information of 8 fixed facilities is also listed in Table 5. We note that the hospital has the demand of compound departments in practice. That is to say, some departments may be required to be located closely together. In this paper, gynecology and obstetrics must be located on the same floor as the B-Ultrasound room. Additionally, internal medicine and cardiovascular must be located on the same floor, and radiology and the B-ultrasound room must be located in the overlapping area of two adjacent floors.

Table 3. Parameters of the building.

\begin{tabular}{ccc}
\hline Parameters & Description & Value \\
\hline$l r_{1}$ & Length of the lower row & 130 \\
$w r_{1}$ & Width of the lower row & 21 \\
$l r_{2}$ & Length of the upper row & 110 \\
$w r_{2}$ & Width of the upper row & 13 \\
$w_{c}$ & Width of the corridor & 6 \\
$l_{h}$ & Length of the hall & 33 \\
$f$ & Number of floors & 3 \\
$H$ & The height of each floor & 6 \\
$e$ & Number of elevators & 2 \\
\hline
\end{tabular}


Table 4. Outpatient departments information.

\begin{tabular}{ccc}
\hline No. & Departments & Area \\
\hline 1 & Laboratory & 329 \\
2 & Pediatrics & 492 \\
3 & Radiology & 429 \\
4 & Surgery & 759 \\
5 & Otolaryngology & 429 \\
6 & Gynecology and obstetrics & 762 \\
7 & Cardiovascular & 217 \\
8 & B-Ultrasound room & 427 \\
9 & Internal medicine & 758 \\
10 & Ophthalmology & 429 \\
11 & Stomatology & 566 \\
12 & Chinese medicine & 188 \\
13 & Cardiovascular test room & 235 \\
14 & Gastroscopy room & 508 \\
\hline
\end{tabular}

Table 5. Fixed facilities information.

\begin{tabular}{cccc}
\hline No. & Fixed Facilities & Area & Located Floor \\
\hline 1 & Pharmacy & 566 & 1 \\
2 & Neuroelectric & 247 & 2 \\
3 & Outpatient treatment 1 & 221 & 2 \\
4 & Outpatient treatment 2 & 217 & 3 \\
5 & Outpatient treatment 3 & 215 & 3 \\
6 & Preventive care & 251 & 1 \\
7 & VIP Clinic 1 & 429 & 3 \\
8 & VIP Clinic 2 & 757 & 3 \\
\hline
\end{tabular}

The patient flow refers to the number of patients moving between two departments. Using a process-mining software DISCO, the patient flows between departments $c_{i j}$ are obtained from more than 5 million electronic records of patient's treatments in two years, which are presented in Table 6.

Table 6. Patient flow.

\begin{tabular}{|c|c|c|c|c|c|c|c|}
\hline \multicolumn{8}{|c|}{ a } \\
\hline & Laboratory & Pediatrics & Radiology & Surgery & Otolaryngology & $\begin{array}{c}\text { Gynecology and } \\
\text { Obstetrics }\end{array}$ & Cardiovascular \\
\hline Laboratory & 188,151 & 56,676 & 17,883 & 82 & 5129 & 45,313 & 2535 \\
\hline Pediatrics & 7694 & 1287 & 195 & 0 & 0 & 0 & 0 \\
\hline Radiology & 15,710 & 9386 & 3591 & 133 & 2684 & 18 & 1097 \\
\hline Surgery & 1168 & 0 & 336 & 59 & 0 & 0 & 0 \\
\hline Otolaryngology & 871 & 0 & 544 & 0 & 222 & 0 & 0 \\
\hline $\begin{array}{c}\text { Gynecology and } \\
\text { obstetrics }\end{array}$ & 41,224 & 0 & 74 & 0 & 0 & 782 & 0 \\
\hline Cardiovascular & 9310 & 0 & 692 & 0 & 0 & 0 & 279 \\
\hline $\begin{array}{l}\text { B-Ultrasound } \\
\text { room }\end{array}$ & 8338 & 6234 & 2110 & 97 & 201 & 6325 & 25 \\
\hline $\begin{array}{l}\text { Internal } \\
\text { medicine }\end{array}$ & 4886 & 0 & 1352 & 0 & 0 & 0 & 0 \\
\hline Ophthalmology & 950 & 0 & 145 & 0 & 0 & 0 & 0 \\
\hline Stomatology & 136 & 0 & 15 & 0 & 0 & 0 & 0 \\
\hline $\begin{array}{l}\text { Chinese } \\
\text { medicine }\end{array}$ & 3886 & 0 & 1142 & 0 & 0 & 0 & 0 \\
\hline $\begin{array}{l}\text { Cardiovascular } \\
\text { test room }\end{array}$ & 794 & 18 & 1095 & 1 & 0 & 8 & 221 \\
\hline $\begin{array}{l}\text { Gastroscopy } \\
\text { room }\end{array}$ & 510 & 4 & 214 & 4 & 4 & 0 & 0 \\
\hline
\end{tabular}


Table 6. Cont.

\begin{tabular}{|c|c|c|c|c|c|c|}
\hline \multicolumn{7}{|c|}{$\mathbf{b}$} \\
\hline $\begin{array}{l}\text { B-Ultrasound } \\
\text { Room }\end{array}$ & Internal Medicine & Ophthalmology & Stomatology & $\begin{array}{l}\text { Chinese } \\
\text { Medicine }\end{array}$ & $\begin{array}{l}\text { Cardiovascular } \\
\text { Test Room }\end{array}$ & $\begin{array}{c}\text { Gastroscopy } \\
\text { Room }\end{array}$ \\
\hline 26,936 & 7571 & 198 & 124 & 1450 & 2751 & 10,258 \\
\hline 246 & 0 & 0 & 0 & 0 & 75 & 1 \\
\hline 2108 & 3264 & 150 & 5 & 7201 & 2908 & 447 \\
\hline 252 & 0 & 0 & 0 & 0 & 1 & 2 \\
\hline 185 & 0 & 0 & 0 & 0 & 1 & 1 \\
\hline 6177 & 0 & 0 & 0 & 0 & 27 & 0 \\
\hline 44 & 0 & 0 & 0 & 0 & 416 & 1 \\
\hline 13,880 & 134 & 2 & 10 & 48 & 607 & 478 \\
\hline 171 & 85 & 0 & 0 & 0 & 27 & 25 \\
\hline 3 & 0 & 114 & 0 & 0 & 2 & 0 \\
\hline 9 & 0 & 0 & 224 & 0 & 0 & 0 \\
\hline 49 & 0 & 0 & 0 & 503 & 16 & 24 \\
\hline 297 & 22 & 0 & 0 & 6 & 1938 & 22 \\
\hline 156 & 9 & 0 & 0 & 3 & 28 & 2097 \\
\hline
\end{tabular}

\subsection{Closeness Rating Score}

Closeness rating is usually used to quantitatively describe the relationships between departments. The closeness rating is used to quantify the non-logistical relationships between departments by six grades: A, E, I, O, U, and X. We acknowledge that, in practice, some departments are not suitable for close placement because of pollution, noise, radiation, cross-infection, and other over-riding factors. The descriptions and corresponding scores of all grades are presented in Table 7.

Table 7. Closeness rating grades.

\begin{tabular}{ccc}
\hline Grades & Descriptions & Scores \\
\hline A & Absolutely necessary & 8 \\
E & Especially important & 4 \\
I & Important & 2 \\
O & Ordinary & 1 \\
U & Unimportant & 0 \\
X & Undesirable & -8 \\
\hline
\end{tabular}

The closeness rating scores chart used in the experiment was obtained from hospital managers and is presented below in Table 8 .

Table 8. Closeness rating scores chart.

\begin{tabular}{|c|c|c|c|c|c|c|c|}
\hline \multicolumn{8}{|c|}{$\mathbf{a}$} \\
\hline & Laboratory & Pediatrics & Radiology & Surgery & Otolaryngology & $\begin{array}{c}\text { Gynecology and } \\
\text { Obstetrics }\end{array}$ & Cardiovascular \\
\hline Laboratory & $\mathrm{NaN}$ & 8 & -8 & 8 & 2 & 8 & 8 \\
\hline Pediatrics & 8 & $\mathrm{NaN}$ & 8 & 2 & 1 & 0 & 0 \\
\hline Radiology & -8 & 8 & $\mathrm{NaN}$ & 8 & 2 & 8 & 8 \\
\hline Surgery & 8 & 2 & 8 & $\mathrm{NaN}$ & 0 & 0 & 0 \\
\hline Otolaryngology & 2 & 1 & 2 & 0 & $\mathrm{NaN}$ & 2 & 1 \\
\hline $\begin{array}{c}\text { Gynecology and } \\
\text { obstetrics }\end{array}$ & 8 & 0 & 8 & 0 & 2 & $\mathrm{NaN}$ & 0 \\
\hline Cardiovascular & 8 & 0 & 8 & 0 & 1 & 0 & $\mathrm{NaN}$ \\
\hline $\begin{array}{l}\text { B-Ultrasound } \\
\text { room }\end{array}$ & -8 & 0 & 0 & 0 & 2 & 8 & 8 \\
\hline $\begin{array}{l}\text { Internal } \\
\text { medicine }\end{array}$ & 8 & 0 & 8 & 0 & 2 & 0 & 8 \\
\hline Ophthalmology & -8 & -8 & 0 & 2 & 4 & 0 & 0 \\
\hline Stomatology & 8 & 2 & 8 & 4 & 4 & 0 & 1 \\
\hline
\end{tabular}


Table 8. Cont.

\begin{tabular}{|c|c|c|c|c|c|c|c|}
\hline \multicolumn{8}{|c|}{$\mathbf{a}$} \\
\hline & Laboratory & Pediatrics & Radiology & Surgery & Otolaryngology & $\begin{array}{c}\text { Gynecology and } \\
\text { Obstetrics }\end{array}$ & Cardiovascular \\
\hline $\begin{array}{l}\text { Chinese } \\
\text { medicine }\end{array}$ & 1 & 4 & 0 & 4 & 4 & 0 & 0 \\
\hline $\begin{array}{l}\text { Cardiovascular } \\
\text { test room }\end{array}$ & 4 & 4 & 4 & 2 & 0 & 2 & 8 \\
\hline $\begin{array}{l}\text { Gastroscopy } \\
\text { room }\end{array}$ & 0 & 0 & 0 & 2 & 0 & 0 & -8 \\
\hline \multicolumn{8}{|l|}{100111} \\
\hline \multicolumn{8}{|c|}{$\mathbf{b}$} \\
\hline $\begin{array}{l}\text { B-Ultrasound } \\
\text { Room }\end{array}$ & \multicolumn{2}{|c|}{ Internal Medicine } & Ophthalmology & Stomatology & $\begin{array}{l}\text { Chinese } \\
\text { Medicine }\end{array}$ & $\begin{array}{l}\text { Cardiovascular } \\
\text { Test Room }\end{array}$ & $\begin{array}{l}\text { Gastroscopy } \\
\text { Room }\end{array}$ \\
\hline-8 & \multicolumn{2}{|l|}{8} & -8 & 8 & 1 & 4 & 0 \\
\hline 0 & \multicolumn{2}{|l|}{0} & -8 & 2 & 4 & 4 & 0 \\
\hline 0 & \multicolumn{2}{|l|}{8} & 0 & 8 & 0 & 4 & 0 \\
\hline 0 & \multicolumn{2}{|l|}{0} & 2 & 4 & 4 & 2 & 2 \\
\hline 2 & \multicolumn{2}{|l|}{2} & 4 & 4 & 4 & 0 & 0 \\
\hline 8 & \multicolumn{2}{|l|}{0} & 0 & 0 & 0 & 2 & 0 \\
\hline 8 & \multicolumn{2}{|l|}{8} & 0 & 1 & 0 & 8 & -8 \\
\hline $\mathrm{NaN}$ & \multicolumn{2}{|l|}{8} & 0 & 0 & 0 & 8 & 0 \\
\hline 8 & \multicolumn{2}{|c|}{$\mathrm{NaN}$} & 1 & 1 & 2 & 2 & 2 \\
\hline 0 & \multicolumn{2}{|c|}{1} & $\mathrm{NaN}$ & 4 & 4 & 0 & 2 \\
\hline 0 & \multicolumn{2}{|l|}{1} & 4 & $\mathrm{NaN}$ & 4 & 0 & 2 \\
\hline 0 & \multicolumn{2}{|l|}{2} & 4 & 4 & $\mathrm{NaN}$ & -8 & 4 \\
\hline 8 & \multicolumn{2}{|l|}{2} & 0 & 0 & -8 & $\mathrm{NaN}$ & 0 \\
\hline 0 & \multicolumn{2}{|l|}{2} & 2 & 2 & 4 & 0 & $\mathrm{NaN}$ \\
\hline
\end{tabular}

\subsection{The Effect of Adaptive Local Search}

In order to evaluate the performance of our proposed algorithm, especially the proposed adaptive local search operator, our algorithm is compared to the standard NSGAII [45]. The difference between our algorithm and the standard NSGA-II is that ours invokes an adaptive local search operator, which is not present in the latter. In addition, we perform a comparison of our adaptive method and that of using the local search operators for every iteration. The parameters used in our algorithms are presented in Table 9. We note that a single run may not produce enough good solutions due to the inherent randomness of the algorithm. Therefore, each algorithm was run 100 times to produce as many good solutions as possible. The output results were combined, and all Pareto-optimal solutions were filtered out. The results and comparisons are presented in Table 10. Figure 5 shows all Pareto-optimal solutions found by each algorithm. The set coverage and spacing metrics from Collette and Siarry [46] are used to assess the convergence and diversity of these algorithms. The results are presented in Tables 11 and 12. In Table 10, we can see that the introduction of an adaptive local search operator leads to better results in terms of total movement distance. However, in terms of total closeness rating score, there was no significant improvement between the standard NSGA-II and our proposed algorithm. Performing a local search in for iteration can decrease total movement distance a lot, but fails to increase the total closeness rating score producing even worse results than the standard NSGA-II. As for CPU time, our adaptive local search operator just needs several additional seconds to obtain better results, while performing a local search in every iteration requires a much longer period of time (22.56 vs. 441.54). In Tables 11 and 12, our algorithm outperforms the standard NSGA-II in both convergence and spacing metrics. Even though performing a local search in every iteration can produce the best results in both convergence and spacing metrics, it takes too long and is thus not practical. 
Table 9. The parameters used in our algorithm.

\begin{tabular}{cc}
\hline Size of population $(P s)$ & 100 \\
Cross-over probability $(p c)$ & 0.8 \\
Mutation probability $(p m)$ & 0.1 \\
Individuals for local search $(P n)$ & $0.1 P S$ \\
Maximum number of iterations $\left(i t e r_{\text {max }}\right)$ & 100 \\
Probabilities of mutation methods $(p 1, p 2, p 3)$ & $0.6,0.2,0.2$ \\
Threshed similarity $(\beta)$ & 0.9 \\
\hline
\end{tabular}

Table 10. Comparison of results.

\begin{tabular}{lcccc}
\hline \multicolumn{2}{c}{ Comparing Methods } & Standard NSGA-II & $\begin{array}{c}\text { NSGA-II with a Local } \\
\text { Search Performed in } \\
\text { Every Iteration }\end{array}$ & $\begin{array}{c}\text { NSGA-II with } \\
\text { Adaptive Local Search }\end{array}$ \\
\hline $\begin{array}{c}\text { Total movement } \\
\text { distance }\end{array}$ & Best & $12,933,696.13$ & $12,637,313.96$ & $12,705,847.76$ \\
Total closeness rating & AVG & $16,619,552.49$ & $15,302,851.60$ & $16,121,966.65$ \\
score & Best & 64 & 62 & 64 \\
& AVG & 55.33333 & 53.28 & 55.74 \\
& & 19.46 & 441.54 & 21.39 \\
\hline
\end{tabular}

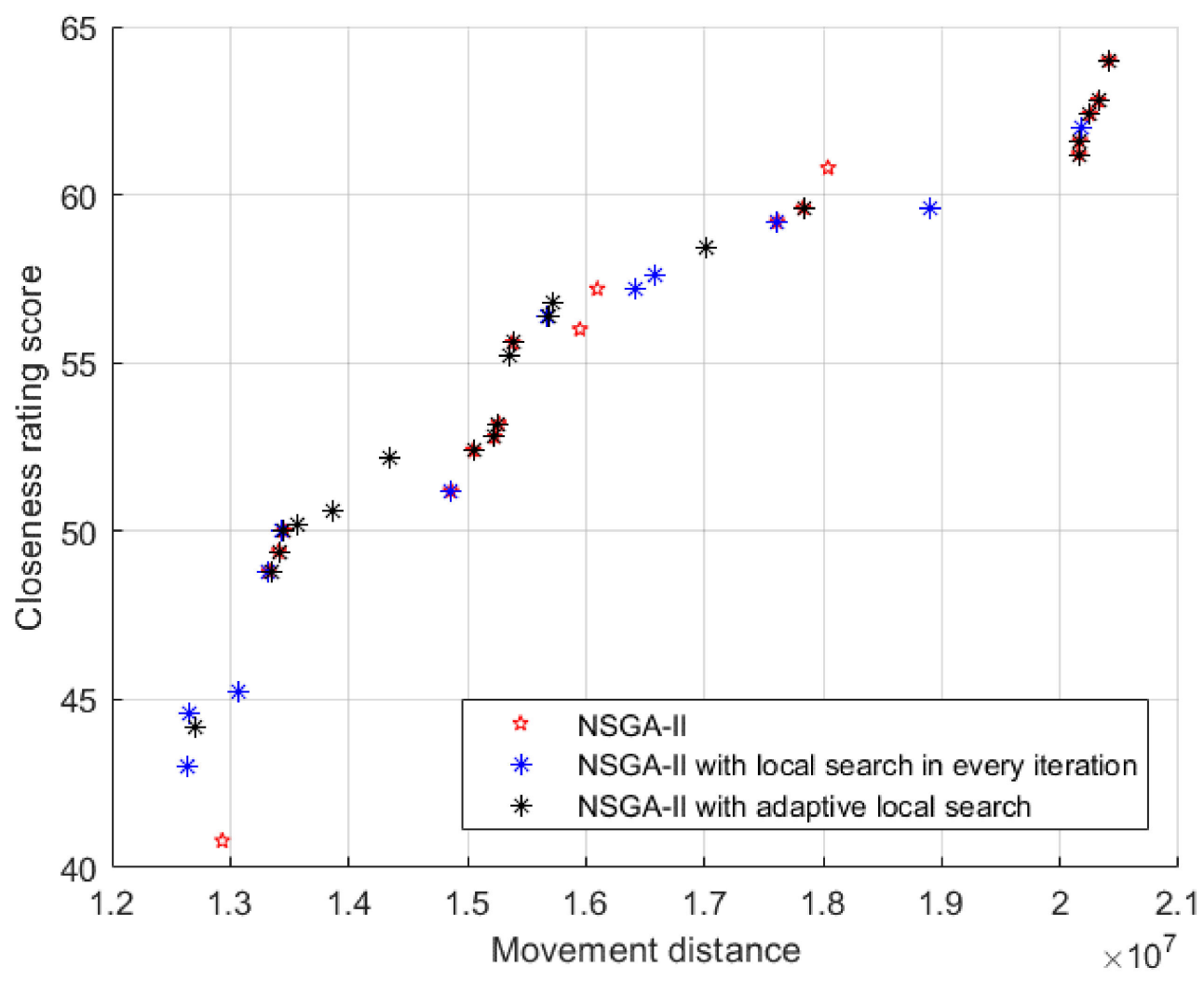

Figure 5. Pareto-optimal solutions. 
Table 11. Convergence metric.

\begin{tabular}{ccccc}
\hline & Standard NSGA-II & $\begin{array}{c}\text { NSGA-II with a Local Search } \\
\text { Performed in Every Iteration }\end{array}$ & $\begin{array}{c}\text { NSGA-II with } \\
\text { Adaptive Local } \\
\text { Search }\end{array}$ & Total \\
\hline $\begin{array}{c}\text { Standard NSGA-II } \\
\text { NSGA-II with a local } \\
\text { search performed in } \\
\text { every iteration }\end{array}$ & 0 & 0.095238095 & 0.047619048 & 0.142857143 \\
$\begin{array}{c}\text { NSGA-II with } \\
\text { adaptive local search }\end{array}$ & 0.157894737 & 0 & 0.19047619 & 0.348370927 \\
\hline
\end{tabular}

Table 12. Spacing metric.

\begin{tabular}{ccc}
\hline Standard NSGA-II & $\begin{array}{c}\text { NSGA-II with a Local Search Performed in } \\
\text { Every Iteration }\end{array}$ & NSGA-II with Adaptive Local Search \\
\hline 1.026321 & 1.018045 & 1.020804 \\
\hline
\end{tabular}

In conclusion, the results clearly show that the introduction of the adaptive local search operator leads to better solutions in terms of both the best and the average values of two objective functions. Additionally, in comparison to performing a local search in every iteration, the adaptive local search operator can obtain results of little difference in a very short period of time.

\subsection{Comparison with Actual Layout}

The actual layout of the hospital is depicted in Figure 6, and the total movement distance and total closeness rating score are easy to calculate, 20,397,091.34 and 34.8, respectively. The comparison is showed in Table 13. In terms of the two objectives, our method can improve upon the actual layout by up to $37.71 \%$ and $83.91 \%$, with an average of $20.96 \%$ and $60.16 \%$. This result means that our method can significantly reduce the unnecessary movement of patients, thus improving their medical experience and relieving their burden. The solution with minimal total movement distance is decoded into a layout in Figure 7. As we can see, the biggest difference is that the distance between the obstetrics and gynecology department and the B-ultrasound room, and the distance between the laboratory and the radiology department are reduced, between which the flow of patients is relatively high. As for closeness, the layouts obtained by our method are also better than the actual layout in terms of cleanness, pollution, noise, and other qualitative requirements.

Table 13. Comparison with actual layout.

\begin{tabular}{lccc}
\hline & & Total Movement Distance & Total Closeness Rating Score \\
\hline Actual layout & & $20,397,091.34$ & 34.8 \\
\hline \multirow{2}{*}{ Results of our method } & Best & $12,705,847.76$ & 64 \\
& AVG & $16,121,966.65$ & 55.7368 \\
\multirow{2}{*}{ Improvement } & Best & $83.91 \%$ & $60.16 \%$ \\
& AVG & $37.71 \%$ & $20.96 \%$ \\
\hline
\end{tabular}




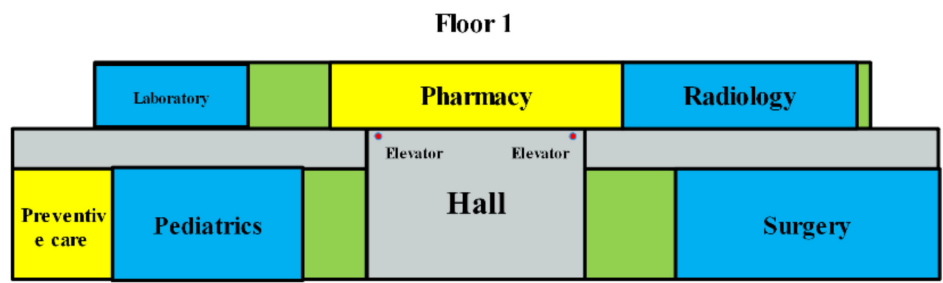

Floor 2

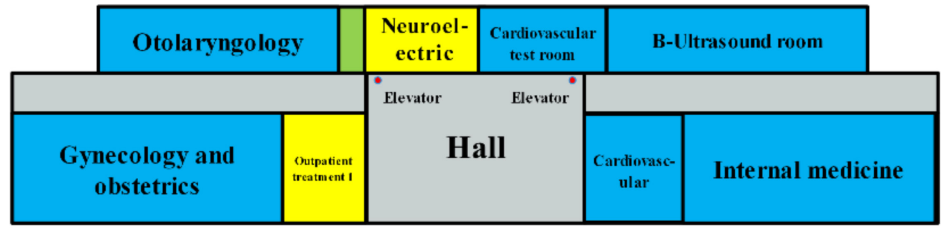

Floor 3

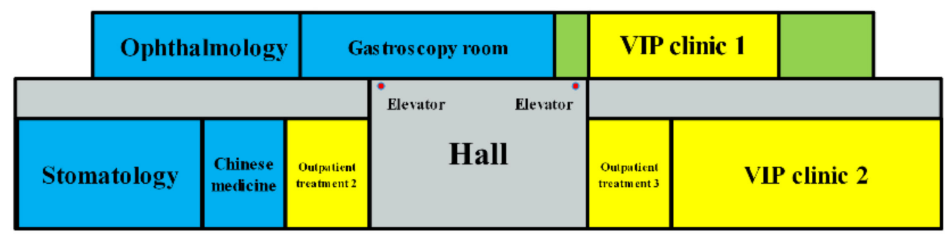

Figure 6. The actual layout of the hospital.

Floor 1

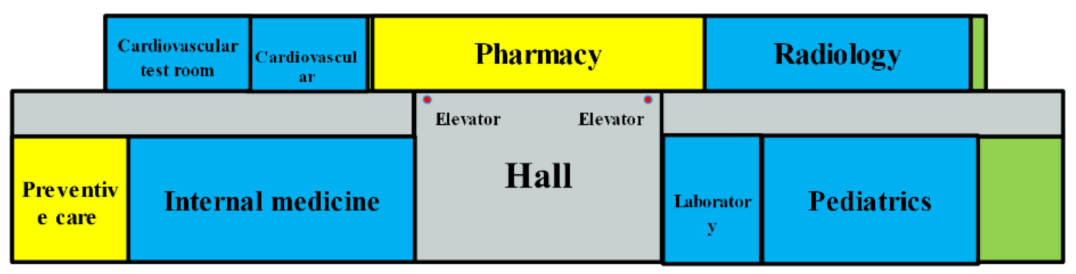

Floor 2

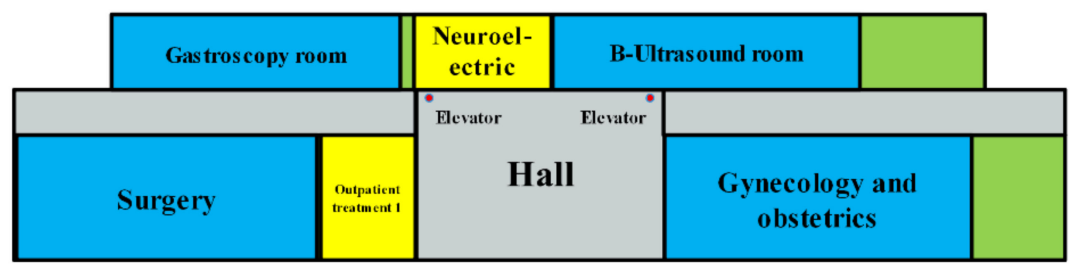

Floor 3

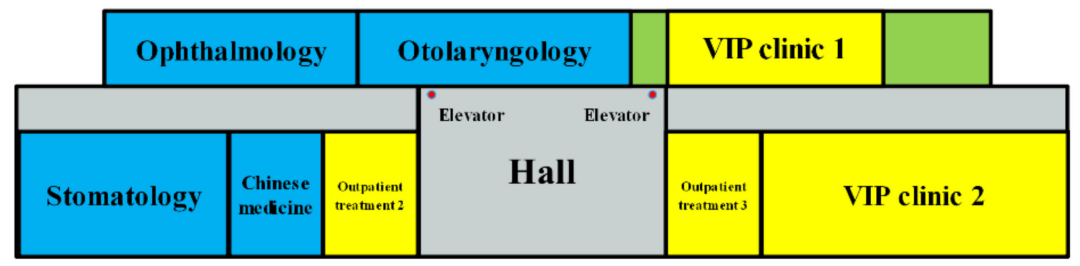

Figure 7. The layout with minimal total movement distance.

\section{Conclusions and Discussions}

In this paper, we demonstrate that our novel double-row model for a multi-floor HFLP considers some fixed facilities. This model enables two objectives, namely movement distance of patients and closeness rating of departments, to be considered simultaneously. These intractable problems have many intrinsic complexity factors within them, and it is often too time-consuming to solve them with exact procedures. Therefore, we offer this 
NSGA-II algorithm with an adaptive local search operator to solve the model and produce a set of Pareto-optimal solutions. Experiment results clearly show that our method can solve the problem successfully and the adaptive local search operator performs well. In terms of the two objectives, our method can improve upon the actual layout by up to $37.71 \%$ and $83.91 \%$, with an average of $20.96 \%$ and $60.16 \%$. This means that our method can lead to less unnecessary movement of patients and higher closeness between departments, thus higher efficiency of the hospital. Moreover, by replacing one of the objective functions, that is, minimizing the total movement distance of patients, with minimizing the total material handling cost, our model can also be applied to facility layout problems in the manufacturing industry.

In this paper, we integrate qualitative factors into a single closeness rating chart. This may not fully reflect the requirement of the hospital layout design. An effort could be made to specify additional qualitative factors and consider more objectives or constraints to enhance the model. Besides, our model and method have certain requirements for the spatial structure of the layout. That is to say, it can only be a double-row structure. The model and method proposed in this paper are not applicable to the facility layout problems of other structures, such as three-row, ring, unequal-area, etc. In future, the hospital layout problem of other layout structures may be a good area for further research. We note that the area requirements of departments may be flexible in practice. The area requirements of some departments can be appropriately reduced when the available floor space is relatively small, rather than fixed as in this paper. How to handle this flexible area requirement within the hospital facility layout problem may be another future research point.

Author Contributions: Conceptualization, J.H.; methodology, J.L.; software, J.L.; validation, J.H., J.L. and H.G.; formal analysis, J.L.; investigation, J.L.; resources, J.L.; data curation, J.L.; writing—original draft preparation, J.L.; writing-review and editing, H.G.; visualization, J.L.; supervision, J.H.; project administration, J.H.; funding acquisition, J.H. All authors have read and agreed to the published version of the manuscript.

Funding: This research was funded by the National Natural Science Foundation of China grant number 71532015 .

Institutional Review Board Statement: Not applicable.

Informed Consent Statement: Informed consent was obtained from all subjects involved in the study.

Data Availability Statement: The data are not publicly available due to it is only available to the members of the research team.

Acknowledgments: This research is supported by the National Natural Science Foundation of China (Grant Nos. 71532015).

Conflicts of Interest: The authors declare no conflict of interest.

\section{References}

1. Chraibi, A.; Kharraja, S.; Osman, I.H.; Elbeqqali, O. A multi-objective mixed-integer programming model for a multi-section operating theatre facility layout. In Proceedings of the International Conference on Operations Research and Enterprise Systems, Angers, France, 6-8 March 2014.

2. Chraibi, A.; Kharraja, S.; Osman, I.H.; Elbeqqali, O. Solving Operating Theater Facility Layout Problem using a Multi-Agent System. In Proceedings of the IEEE-2nd International Conference on Control, Decision and Information Technologies, Metz, France, 3-5 November 2014.

3. Kharraja, S.; Elbeqqali, O.; Osman, I.H.; Elbeqqali, O. A mixed integer programming formulation for solving operating theatre layout problem: A multi-goal approach. In Proceedings of the International Conference on Industrial Engineering \& Systems Management, Rabat, Morocco, 28-30 October 2014.

4. Rismanchian, F.; Lee, Y.H. Process Mining-Based Method of Designing and Optimizing the Layouts of Emergency Departments in Hospitals. Herd 2017, 10, 105-120. [CrossRef] [PubMed]

5. Kotzer, A.M.; Zacharakis, S.K.; Raynolds, M.; Buenning, F. Evaluation of the Built Environment: Staff and Family Satisfaction Preand Post-Occupancy of The Children's Hospital. Herd 2011, 4, 60-78. [CrossRef]

6. Ulrich, R.S.; Zhu, X. Medical Complications of Intra-Hospital Patient Transports: Implications for Architectural Design and Research. Herd 2007, 1, 31. [CrossRef] [PubMed] 
7. Garcia-Hernandez, L.; Pierreval, H.; Salas-Morera, L.; Arauzo-Azofra, A. Handling qualitative aspects in Unequal Area Facility Layout Problem: An Interactive Genetic Algorithm. Appl. Soft Comput. 2013, 13, 1718-1727. [CrossRef]

8. Ripon, K.S.N.; Glette, K.; Khan, K.N.; Hovin, M.; Torresen, J. Adaptive variable neighborhood search for solving multi-objective facility layout problems with unequal area facilities. Swarm Evol. Comput. 2013, 8, 1-12. [CrossRef]

9. Vitayasak, S.; Pongcharoen, P.; Hicks, C. A tool for solving stochastic dyna-mic facility layout problems with stochastic demand using either a Genetic Algorithm or modified Backtracking Search Algorithm. Int. J. Prod. Econ. 2017, 190, 146-157. [CrossRef]

10. Benjaafar, S. Modeling and Analysis of Congestion in the Design of Facility Layouts. Manag. Sci. 2002, 48, 679-704. [CrossRef]

11. Singh, S.P.; Sharma, R.R.K. A review of different approaches to the facility layout problems. Int. J. Adv. Manuf. Technol. 2006, 30, 425-433.

12. Emami, S.; Nookabadi, A.S. Managing a new multi-objective model for the dynamic facility layout problem. Int. J. Adv. Manuf. Technol. 2013, 68, 2215-2228. [CrossRef]

13. Mohamadghasemi, A.; Hadi-Vencheh, A. An integrated synthetic value of fuzzy judgments and nonlinear programming methodology for ranking the facility layout patterns. Comput. Ind. Eng. 2012, 62, 342-348. [CrossRef]

14. Pillai, V.M.; Hunagund, I.B.; Krishnan, K.K. Design of robust layout for Dynamic Plant Layout Problems. Comput. Ind. Eng. 2011, 61, 813-823. [CrossRef]

15. Izadinia, N.; Eshghi, K. A robust mathematical model and ACO solution for multi-floor discrete layout problem with uncertain locations and demands. Comput. Ind. Eng. 2016, 96, 237-248. [CrossRef]

16. Hosseini-Nasab, H.; Fereidouni, S.; Ghomi, S.M.T.F.; Fakhrzad, M.B. Classification of facility layout problems: A review study. Int. J. Adv. Manuf. Technol. 2017, 94, 957-977. [CrossRef]

17. Hans, E.W.; Van, M.H.; Hulshof, P.J.H. A Framework for Healthcare Planning and Control. In Handbook of Healthcare System Scheduling: International Series in Operations Research \& Management Science; Hall, R., Ed.; Springer: Boston, MA, USA, 2012; Volume 168, pp. 303-320.

18. Chaudhury, H.; Mahmood, A.; Valente, M. Advantages and Disadvantages of Single-Versus Multiple-Occupancy Rooms in Acute Care Environments A Review and Analysis of the Literature. Environ. Behav. 2005, 37, 760-786. [CrossRef]

19. Joseph, A.; Rashid, M. The architecture of safety: Hospital design. Curr. Opin. Crit. Care 2007, 13, 714-719. [CrossRef] [PubMed]

20. Choudhary, R.; Bafna, S.; Heo, Y.; Hendrich, A.; Chow, M. A predictive model for computing the influence of space layouts on nurses' movement in hospital units. J. Build. Perform. Simul. 2010, 3, 171-184. [CrossRef]

21. Hignett, S.; Lu, J. Space to care and treat safely in acute hospitals: Recommendations from 1866 to 2008. Appl. Ergon. 2010, 41, 666-673. [CrossRef]

22. Yi, L.; Seo, H.B. The Effect of Hospital Unit Layout on Nurse Walking Behavior. HERD Health Environ. Res. Des. J. 2012, 6, 66-82. [CrossRef] [PubMed]

23. Meng, L.; Batt, R.; Terwiesch, C. The Impact of Facility Layout on Service Worker Behavior: An Empirical Study of Nurses in the Emergency Department. Soc. Sci. Electron. Publ. 2018. [CrossRef]

24. Arnolds, I.V.; Nickel, S. Multi-period layout planning for hospital wards. Socio-Econ. Plan. Sci. 2013, 47, 220-237. [CrossRef]

25. Lin, Q.L.; Liu, H.C.; Wang, D.J.; Liu, L. Integrating systematic layout planning with fuzzy constraint theory to design and optimize the facility layout for operating theatre in hospitals. J. Intell. Manuf. 2015, 26, 87-95. [CrossRef]

26. Chraibi, A.; Kharraja, S.; Osman, I.H.; Elbeqqali, O. Optimization of Dynamic Operating Theatre Facility Layout. In Proceedings of the International Conference on Industrial Engineering \& Systems Management, Seville, Spain, 21-23 October 2016.

27. Chraibi, A.; Kharraja, S.; Osman, I.H.; Elbeqqali, O. A Particle Swarm Algorithm for Solving the Multi-objective Operating Theater Layout Problem. IFAC PapersOnLine 2016, 49, 1169-1174. [CrossRef]

28. Lin, Q.L.; Wang, D. Facility Layout Planning with SHELL and Fuzzy AHP Method Based on Human Reliability for Operating Theatre. J. Healthc. Eng. 2019, 2019, 1-12. [CrossRef] [PubMed]

29. Elshafei, A.N. Hospital Layout as a Quadratic Assignment Problem. J. Oper. Res. Soc. 1977, 28, 167-179. [CrossRef]

30. Feng, X.; Su, Q. An applied case of quadratic assignment problem in hospital department layout. In Proceedings of the International Conference on Service Systems \& Service Management, Guangzhou, China, 22-24 June 2015.

31. Helber, S.; BoHme, D.; Oucherif, F.; Lagershausen, S.; Kasper, S. A hierarchical facility layout planning approach for large and complex hospitals. Flex. Serv. Manuf. J. 2016, 28, 5-29. [CrossRef]

32. Arnolds, I.V.; Gartner, D. Improving hospital layout planning through clinical pathway mining. Ann. Oper. Res. 2017, $263,1-25$. [CrossRef]

33. Liang, L.Y.; Chao, W.C. The strategies of tabu search technique for facility layout optimization. Autom. Constr. 2008, 17, 657-669. [CrossRef]

34. Mohamed, A.B.; Gunsekaran, M.; Doaa, E.S.; Seyedali, M. Integrating the whale algorithm with Tabu search for quadratic assignment problem: A new approach for locating hospital departments. Appl. Soft Comput. 2018, 73, 530-546.

35. Tayal, A.; Singh, S.P. Integrating big data analytic and hybrid firefly-chaotic simulated annealing approach for facility layout problem. Ann. Oper. Res. 2018, 270, 489-514. [CrossRef]

36. Tongur, V.; Hacibeyoglu, M.; Ulker, E. Solving a big-scaled hospital facility layout problem with meta-heuristics algorithms. Eng. Sci. Technol. Int. J. 2020, 23, 951-959. [CrossRef]

37. Ma, Y.; Zuo, X.; Huang, X.; Gu, F.; Zhao, X. A MOEA/D based approach for hospital department layout design. In Proceedings of the 2016 IEEE Congress on Evolutionary Computation (CEC), Vancouver, BC, Canada, 24-29 July 2016. 
38. Chraibi, A.; Osman, I.H.; Kharraja, S. Adaptive layout for operating theatre in hospitals: Different mathematical models for optimal layouts. Ann. Oper. Res. 2019, 272, 493-527.

39. Zuo, X.; Li, B.; Huang, X.; Zhou, M.C.; Cheng, C.; Zhao, X. Liu, Z. Optimizing Hospital Emergency Department Layout via Multiobjective Tabu Search. IEEE Trans. Autom. Sci. Eng. 2019, 16, 1137-1147.

40. Chung, J.; Tanchoco, J.M.A. The double row layout problem. Int. J. Prod. Res. 2010, 48, 709-727. [CrossRef]

41. Murray, C.C.; Smith, A.E.; Zhang, Z. An efficient local search heuristic for the double row layout problem with asymmetric material flow. Int. J. Prod. Res. 2013, 51, 6129-6139. [CrossRef]

42. Zuo, X.; Murray, C.C.; Smith, A.E. Solving an Extended Double Row Layout Problem Using Multiobjective Tabu Search and Linear Programming. IEEE Trans. Autom. Sci. Eng. 2014, 11, 1122-1132. [CrossRef]

43. Wang, S.; Zuo, X.; Liu, X.; Zhao, X.; Li, J. Solving dynamic double row layout problem via combining simulated annealing and mathematical programming. Appl. Soft Comput. 2015, 37, 303-310. [CrossRef]

44. Amaral, A.R.S. A mixed-integer programming formulation for the double row layout of machines in manufacturing systems. Int. J. Prod. Res. 2019, 57, 34-47.

45. Deb, K.; Pratap, A.; Agarwal, S.; Meyarivan, T. A fast and elitist multi-objective genetic algorithm: NSGA-II. IEEE Trans. Evol. Comput. 2002, 6, 182-197. [CrossRef]

46. Collette, Y.; Siarry, P. Three new metrics to measure the convergence of metaheuristics towards the Pareto frontier and the aesthetic of a set of solutions in biobjective optimization. Comput. Oper. Res. 2005, 32, 773-792. [CrossRef] 